\title{
Glucocorticoids Modulate Macrophage Surface Oligosaccharides and Their Bone Binding Activity
}

\author{
Zvi Bar-Shavit, Arnold J. Kahn, Lyle E. Pegg, \\ Kenneth R. Stone, and Steven L. Teitelbaum \\ Departments of Pathology and Medicine, The Jewish Hospital of \\ St. Louis, Washington University School of Medicine, and \\ Division of Cell Biology, Washington University School of \\ Dental Medicine, St. Louis, Missouri 63110
}

bstract. The circumstantial evidence that indicates that glucocorticoids (GC) may stimulate osteoclastic resorption in vivo has recently found support in observations that demonstrate that these compounds effectively increase the activity of isolated resorptive cells (osteoclasts, macrophage polykaryons, and elicited macrophages [MO]) in vitro. Data are presented here that indicate that this stimulation by GC is due to an enhancement of the initial stage of the resorption process, the attachment of cells to bone, and that this is caused by alterations of cell surface oligosaccharides. Specifically, dexamethasone and cortisol enhance by $80 \%$ the attachment of MO to bone surfaces in a dose dependent manner but do not alter or reduce the binding of these cells to other surfaces (plastic, collagen, and hydroxyapatite crystals). The effect of GC on cell-bone attachment is blocked by the glycosylation inhibitor, tunicamycin, and the glycosylation modifier, swainsonine; this demonstrates that asparagine-linked oligosaccharides are involved in the stimulatory process. Flow cytometric analysis of GCtreated cells using a panel of fluoresceinated lectins confirms this by indicating a selective, enhanced exposure of plasma membrane-associated $N$-acetylglucosamine and $N$-acetylgalactosamine residues, sugars we have previously shown to be pivotal in MO-bone binding. Finally, progesterone, a known GC antagonist, blocks GC-stimulated resorption, macrophage-bone binding, and membrane oligosaccharide modification, presumably by competing

Dr. Bar-Shavit is the recipient of an Arthritis Investigator Award from the Arthritis Foundation.

Received for publication 21 October 1983 and in revised form 29 December 1983.

J. Clin. Invest.

(c) The American Society for Clinical Investigation, Inc. 0021-9738/84/05/1277/07 \$1.00

Volume 73, May 1984, 1277-1283 for the GC receptor. Progesterone alone alters none of these processes. Thus, GC stimulates the resorptive activity of macrophages by enhancing the initial events in the degradative process (cell-bone binding) and does so, apparently, via receptor-mediator alteration of cell surface glycoproteins.

\section{Introduction}

One of the most common forms of treatment of inflammatory and immune-related disorders is the administration of glucocorticoids (GC). ${ }^{1}$ These steroidal compounds are clearly effective in the short term, but their chronic administration results in a number of unwanted side effects, of which the most important are loss of bone (osteopenia) and spontaneous fracture. Because of the clinical importance of GC, these observations have prompted many studies that aimed to elucidate the mechanism of action of these compounds at the cellular level in bone.

The maintenance of skeletal mass is the result of a balance between bone formation and resorption. Consequently, steroidinduced osteopenia may result from decreased bone formation, increased resorption, or a combination of both. Studies of the effects of GC on the skeleton uniformly indicate that these compounds inhibit osteoblastic function (1-4) (i.e., bone formation) but are less clear about how they affect osteoclasts (i.e., bone resorption). For example, GCs usually block parathyroid hormone-stimulated resorption in fetal bone rudiments in organ culture (5), but histological examination of these tissues taken from GC-treated patients and animals indicates an increase in the number of osteoclasts and no apparent decrease in resorptive activity $(1,2,5-9)$.

1. Abbreviations used in this paper: DBA, Dolichos Biflourus agglutinin; FITC, fluoresceine isothiocyanate; GC, glucocorticoids; GSA-2, Griffonia Simplicifolia 2; $\alpha$-MEM, Eagle's Minimal Essential Medium, $\alpha$-modification; MO, macrophages; $\alpha$-MOPS, Eagle's Minimal Essential Medium, $\alpha$-modification, buffered to $\mathrm{pH} 7.4$ with 3 ( $N$-morpholino); SBA, soybean agglutinin; SW, swainsonine; TM, tunicamycin; WGA, wheat germ agglutinin. 
Previous attempts to explain the foregoing observation have focused largely on the observation that GC-treated patients or animals may develop secondary hyperparathyroidism, presumably through suppressed intestinal absorption of calcium $(1,2)$. The logical consequence of this model is that the osteoclastic proliferation which accompanies GC treatment is mediated through parathyroid hormone secretion and that GC per se, do not directly stimulate bone resorption. This hypothesis, however, remains unproven and is particularly weakened by the observation that most GC-treated patients do not develop secondary hyperparathyroidism (2).

Another explanation that might account for the apparent stimulation by GCs of resorption in vivo is the simplest one, namely, that these steroids enhance skeletal degradation by directly promoting the activity of resorptive cells. This hypothesis follows largely from the very recent observation that bone resorption by isolated osteoclasts in vitro is significantly enhanced by GC (M. Fallon, personal communication) and from our previous studies showing that a similar effect can be documented for other differentiated cells that belong to the mononuclear phagocyte family, i.e., macrophages (MO) (10) and MO polykaryons (multinucleated giant cells) (11).

In this study, we examine the mechanisms of GC-stimulated resorption, particularly as it relates to the ability of resorptive cells to attach to bone, a step essential to efficient matrix degradation. The data show that GC markedly and specifically increase cell-bone binding and indicate that this stimulation is likely the result of alterations of cell surface glycoproteins.

\section{Methods}

The materials used in this study were obtained from the following sources: steroids and sugars, Sigma Chemical Co. (St. Louis, MO); tunicamycin (TM), Calbiochem-Behring Corp., American Hoescht Corp. (La Jolla, CA); swainsonine (SW), Dr. P. Stahl (Washington University, St. Louis, MO); Eagle's Minimal Essential Medium ( $\alpha$-modification, $\alpha$-MEM), KC Biological, Inc. (Lenexa, KS); fetal bovine serum, Dutchland (Denver, PA); hydroxyapatite particles, Dr. P. Hauschka (Harvard University, Cambridge, MA). fluoresceine isothiocyanate (FITC) conjugates of the following lectins were obtained from EY Laboratories (San Mateo, CA): peanut agglutinin, Concanavalin A, Dolichos Biflourus agglutinin (DBA), Ricinus Communis agglutinin 1, Griffonia Simplicifolia 2 (GSA-2), wheat germ agglutinin (WGA), and soybean agglutinin (SBA).

\section{Binding assays}

Particle binding. This method is described in detail in a previous publication (12). Briefly, rat thioglycollate-elicited peritoneal cells are suspended in $\alpha$-MOPS [ $\alpha$-MEM buffered to pH 7.4 with 3( $N$-morpholino) propanesulfonic acid] at a concentration of $5 \times 10^{5} / \mathrm{ml}$ and $0.2-\mathrm{ml}$ aliquots are pipetted into 6-mm-diam multiwell plates. After $1 \mathrm{~h}$ of incubation at $37^{\circ} \mathrm{C}$, the cultures are rinsed and the medium is replaced with bicarbonate buffered $\alpha$-MEM supplemented with $2.5 \%$ fetal calf serum that contains the GC or the vehicle (ethanol). The plates are then incubated for various lengths of time and rinsed again to remove the nonadherent cell fraction. $60-70 \%$ of the exudate cells remain attached and, of these, $\sim 98 \%$ are $\mathrm{MO}$ as assessed by esterase staining and phagocytosis.
${ }^{45} \mathrm{Ca}$-labeled bone particles $23-43 \mu \mathrm{m}$ in diameter are added to the MO-containing wells in $0.2-\mathrm{ml}$ aliquots $(1 \mathrm{mg} / \mathrm{ml}$ in $\alpha$-MOPS). The plates are then incubated at $37^{\circ} \mathrm{C}$ in air for an additional hour, and the nonadherent particles are removed by immersion and agitation in three successive changes of phosphate-buffered saline (PBS). 5\% TCA is then added to each well to solubilize the residual attached particles, and the resultant radioactive slurry is dissolved in scintillation fluid (Scintiverse, Fisher Scientific Co., Allied Corp., Pittsburgh, PA) for counting. The net, cell-associated binding of particles is determined by subtracting the counts obtained from particles added to cell-free wells from counts derived from cultures that contain MO monolayers.

Calvarial binding (12). Elicited peritoneal exudate cells in $\alpha$-MOPS are plated into $60-\mathrm{mm}$ tissue culture dishes and rinsed after $1 \mathrm{~h}$ of incubation to remove the nonadherent fraction. Bicarbonate buffered $\alpha$-MEM supplemented with $2.5 \%$ fetal calf serum is then added to the dishes with GC or ethanol and, after an additional 24-72 $\mathrm{h}$ of culture, the plates are rinsed again to remove the remaining nonadherent cells. The medium is then replaced with $\mathrm{Ca}^{++} / \mathrm{Mg}^{++}$-free PBS at $4^{\circ} \mathrm{C}$. 20 min later, the attached $\mathrm{MO}$ are brought into suspension by gentle scraping with a rubber policeman. The MO are then labeled for $1 \mathrm{~h}$ at $37^{\circ} \mathrm{C}$ with $\mathrm{Na}^{51} \mathrm{CrO}_{4}$ (sp act $250-500 \mu \mathrm{Ci} / \mathrm{mg} \mathrm{Cr}$ ) (Amersham Corp., Arlington Heights, IL) $\left(1 \mu \mathrm{Ci} / 10^{6}\right.$ cells in $\alpha$-MOPS), washed three times with cold $\alpha$-MOPS, and suspended in the same medium at $1 \times 10^{6} \mathrm{cells} / \mathrm{ml} .0 .1$ $\mathrm{ml}$ aliquots of the cell suspension are then pipetted onto the endocranial surface of freshly dissected rat calvaria that are obtained from 7-d-old rat pups and freed of their inner periosteum by mechanical stripping. The calvaria are placed, concave-side up, in multiwell culture dishes and the cells are added. After $1 \mathrm{~h}$ of incubation, the nonadherent cells are removed by sequentially rinsing the calvaria in PBS, and the adherent fraction is determined by $\gamma$-scintography.

Hydroxyapatite binding. The protocol used is identical to the boneparticle binding assay. The particles are labeled by incubation with ${ }^{45} \mathrm{Ca}$ (100 $\mu \mathrm{Ci} / 10 \mathrm{mg}$ per ml PBS) for $24 \mathrm{~h}$.

\section{Bone resorption}

The extent of bone resorption is established from the cell-mediated ${ }^{45} \mathrm{Ca}$ release from devitalized labeled bone particles as previously described (13).

\section{Cell number}

The number of adherent cells is determined by the methylene blue binding technique (14). In brief, cells are fixed overnight in $2.5 \%$ formaldehyde, washed in $0.1 \mathrm{M}$ borate buffer ( $\mathrm{pH} 8.5$ ), and incubated for $10 \mathrm{~min}$ in methylene blue $(1 \mathrm{mg} / \mathrm{ml}$ in borate buffer). The cells are then washed extensively in buffer to remove excess dye and extracted with $0.1 \mathrm{~N} \mathrm{HCl}$ at $37^{\circ} \mathrm{C}$ for $40 \mathrm{~min}$ to elute the cell-associated methylene blue. The eluate is measured spectrophotometrically at $650 \mathrm{~nm}$. Dye binding is proportional to cell number (14). This method is used to assure that the increase in bone-particle binding is not a result of increased MO attachment to the wells.

\section{Flow cytometric analysis of FITC-lectins binding}

Cells are prepared as for the calvarial binding assay but are not radiolabeled. After the cells are brought into suspension they are washed three times in PBS and resuspended to $2 \times 10^{6} / 0.5 \mathrm{ml}$ in PBS. FITC lectins are then added to the suspension in the presence or absence of the competing sugars for $60 \mathrm{~min}$ at $4^{\circ} \mathrm{C}$. After three washes in PBS, the cells are suspended in PBS $\left(2 \times 10^{6} / 2 \mathrm{ml}\right)$ kept on ice, and analyzed immediately in a fluorescence-activated cell sorter (Epics V, Coulter Electronics Inc., Hialeah, FL). 


\section{Results}

Incubation of MO with cortisol or dexamethasone significantly enhances cell-bone binding by $24 \mathrm{~h}$ and produces optimal stimulation by $48 \mathrm{~h}$. At the later time, attachment is increased $\sim 175 \%$ relative to untreated cells and is evident whether binding is measured by the particle (Fig. 1) or calvarial (Fig. 2) assay. The stimulation of MO-bone binding by GC is dose dependent and is elicited at both physiological and pharmacological concentrations (Fig. 3). In contrast, progesterone (Figs. 1-3) and 11deoxycortisol (not shown) do not alter MO-bone binding.

Because MOs bind to a remarkably broad spectrum of substrates, it was of interest to determine the specificity of the GCstimulated attachment process. To this end, MO were preincubated with cortisol $\left(10^{-6} \mathrm{M}\right)$ or dexamethasone $\left(10^{-8} \mathrm{M}\right)$ and later assayed for their ability to bind ${ }^{45} \mathrm{Ca}$-labeled hydroxyapatite particles, or, after radiolabeling with ${ }^{51} \mathrm{Cr}$, to tissue culture plastic. Fig. 4 shows that treatment with GC either had no effect or reduced the ability of MO to bind to hydroxyapatite or plastic. Similar results were obtained when a reconstituted Type I, collagen-coated surface was used as an attachment substrate for GC-treated MO (data not shown).

Membrane oligosaccharides are known to play a role in the recognition and attachment of cells to specific substrates, and we have previously shown (12) that such sugar residues are also important in resorptive cell-bone binding. We therefore examined the possibility that the enhancement of MO-bone attachment induced by GCs is caused by the alteration of membrane oligosaccharides. The first such experiments involved the use of tunicamycin (TM) (a glycosylation inhibitor) or swain-

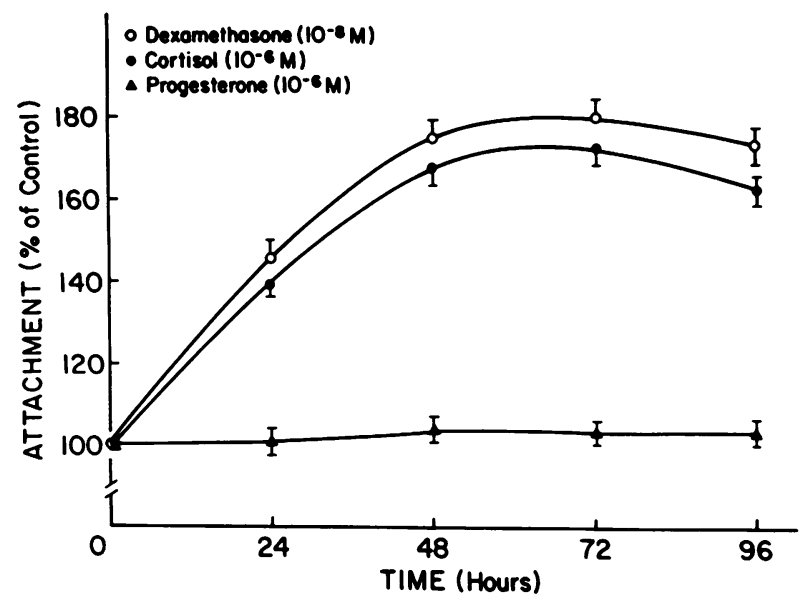

Figure 1. GC stimulation of bone particle binding by elicited MO. MO monolayers were pretreated with dexamethasone $\left(10^{-8} \mathrm{M}\right)$, cortisol $\left(10^{-6} \mathrm{M}\right)$, or progesterone $\left(10^{-6} \mathrm{M}\right)$ for the times indicated. The steroids were then removed, ${ }^{45} \mathrm{Ca}$-labeled bone particles were added, and the fraction of the particles bound after $1 \mathrm{~h}$ more of incubation was determined. Note that dexamethasone and cortisol, but not progesterone, significantly stimulate binding activity. Each point represents the mean of six replicate cultures \pm SEM.

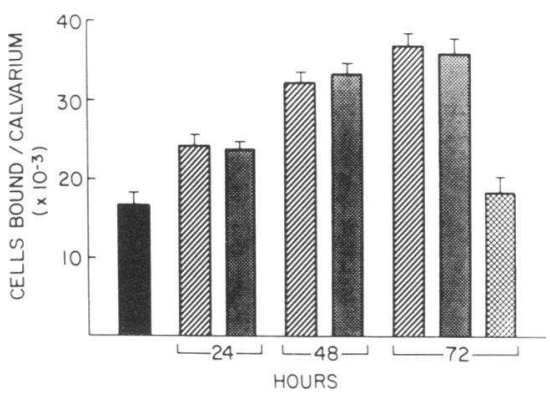

Figure 2. GC stimulation of MO attachment to exposed calvarial bone surfaces. Cells are preincubated with dexamethasone $\left(10^{-8} \mathrm{M}\right)$, cortisol $\left(10^{-6} \mathrm{M}\right)$, or progesterone $\left(10^{-6} \mathrm{M}\right)$ for the times indicated, rinsed, and removed from the culture dishes as described in Methods. The cells were then labeled with ${ }^{51} \mathrm{Cr}$ and added by aliquots onto the stripped endocranial surface of freshly dissected calvaria. After $1 \mathrm{~h}$ of incubation, the fraction of adherent cells was determined indirectly from the radioactivity associated with sequentially rinsed calvaria. Each point represents the mean counts from three calvaria. (Control, solid bars; cortisol, hatched bars; dexamethasone, stippled bars; progesterone, cross-hatched bars.)

sonine (SW) (an agent known to alter glycosylation). Fig. 5 shows that each of these agents reduced basal (no cortisol) MObone attachment and blocked the stimulatory effect of cortisol on this process. Such inhibition of bone attachment was unassociated with change in cell number (data not shown).

These observations led us to test directly the effect of GC on the accessibility of cell surface oligosaccharides. Here, quantitative flow cytometry was used to analyze the binding of specific FITC-conjugated lectins by GC-treated and control MO. Fig. 6 demonstrates that GC treatment enhances the binding of WGA and DBA, lectins that are specific for $N$-acetylglucosamine and $N$-acetylgalactosamine, which are sugars we have previously shown (12) to be important for the bone attachment activity

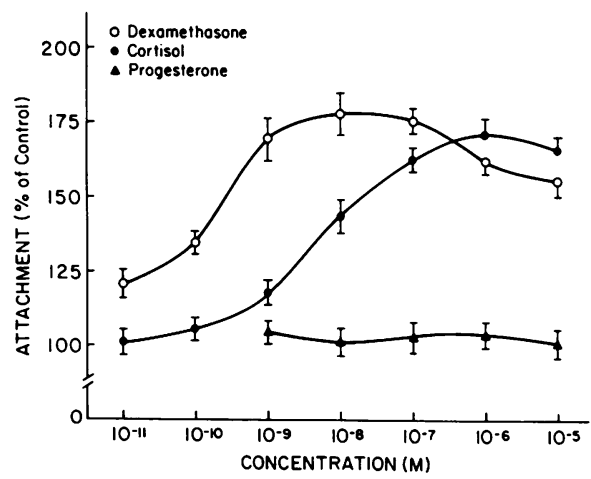

Figure 3. Attachment of bone as a function of steroid concentration. MO monolayers were preincubated for $72 \mathrm{~h}$ with the indicated concentrations of dexamethasone, cortisol, or progesterone, and then assayed for binding activity. The data show that the GCs markedly increase particle attachment, whereas progesterone is ineffective. Each point represents the mean \pm SEM for six replicate cultures. 


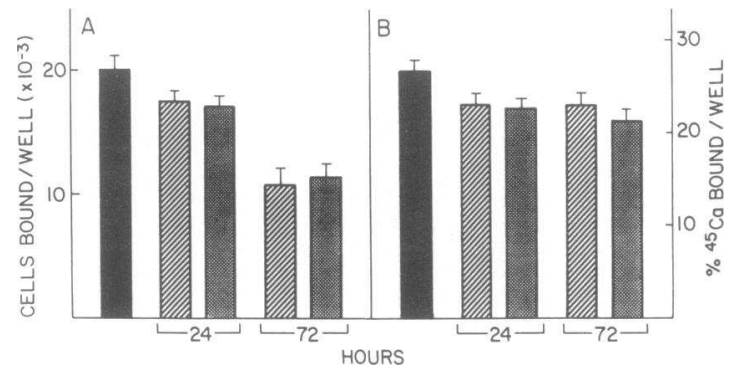

Figure 4. The effect of GC on the ability of MO to bind to plastic $(A)$ and hydroxyapatite $(B)$. Note that compared with the stimulatory effect of $\mathrm{GC}$ on MO-bone binding, dexamethasone $\left(10^{-8} \mathrm{M}\right.$; hatched bars) and cortisol $\left(10^{-6} \mathrm{M}\right.$; solid bars) reduce attachment to these alternative substrates. The binding assays were performed as described for bone particles (hydroxyapatite) or calvaria (plastic) and followed a preincubation period of $72 \mathrm{~h}$. Control, solid bars.

of MO. We obtained similar results with the lectins GSA-2 and SBA (data not shown). On the other hand, no changes are evident in the binding of lectins specific for sugars that do not affect the cell bone attachment; for example, concanavalin, A specific for mannose residues, and Ricinus Communis agglutinin and peanut agglutinin, specific for galactose.

The final group of experiments tried to establish whether the action of GC on MO is mediated through cytosolic receptors. We took advantage of the established ability of progesterone to compete for the $\mathrm{GC}$ receptor and found that, whereas progesterone alone does not affect MO-bone attachment, it inhibits the GC stimulation of the binding process (Fig. 7). In a similar way, progesterone restricts the ability of dexamethasone to en-

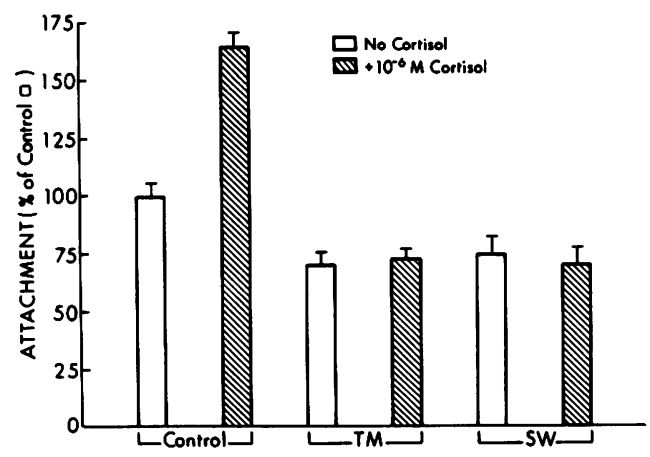

Figure 5. Effect of the glycosylation inhibitor, TM, and the glycosylation modifier, SW, on cortisol-stimulated MO-bone attachment. MO monolayers were cultured with $10^{-6} \mathrm{M}$ cortisol or the alcohol carrier for $48 \mathrm{~h}$, followed by $24 \mathrm{~h}$ of concurrent incubation with TM $(0.2$ $\mu \mathrm{g} / \mathrm{ml})$ or SW $(0.1 \mu \mathrm{g} / \mathrm{ml})$. The cells were then washed and assessed for particle binding as previously described. Note that TM and SW significantly $(P<0.001)$ inhibit both basal and cortisol-stimulated binding.

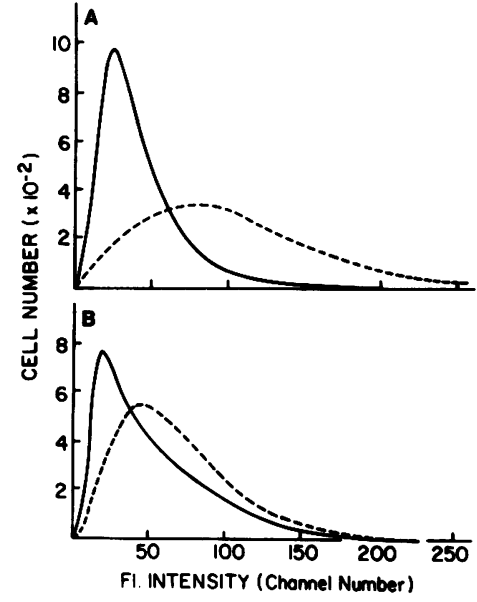

Figure 6. Effect of GC on the binding of FITC-DBA $(A)$ and FITC-WGA $(B)$ to MO. Cells were preincubated with dexamethasone $\left(10^{-8} \mathrm{M}\right.$, dashed line) or the alcohol carrier (solid line) for $\mathbf{4 8} \mathrm{h}$, rinsed, and conjugated to one or the other fluoresceinated lectin. The labeled cells were then analyzed for fluorescence intensity by flow cytometry (see Methods). Note the significant shift in lectin binding (Fl. intensity) as a consequence of $\mathrm{GC}$ treatment.

hance MO-mediated bone resorption (Fig. 8). Finally, the presence of progesterone blocks the development of lectin binding sites (exposed sugar residues) in GC-treated MO (Fig. 9).

\section{Discussion}

Bone resorption is a multistage process that involves, among other things, the attachment of cells to bone (13). In the Introduction, we postulated that the resorption-stimulating activity of GC might be due to a direct effect of the steroids on cells with degradative potential (MO, osteoclasts) and indicated that such stimulation might be a manifestation of enhanced cell attachment to bone surfaces. Indeed, the data show that GC

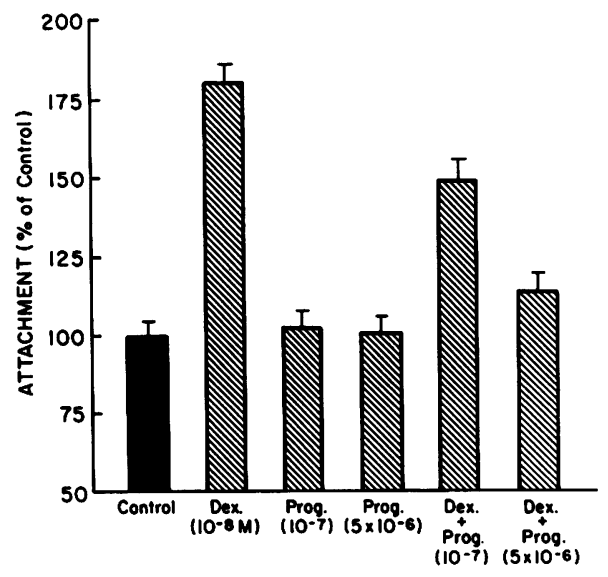

Figure 7. Effect of progesterone on GC-stimulated MO-bone attachment. MO were treated for $48 \mathrm{~h}$ with the agents indicated on the abscissa and then subjected to the bone particle binding assay. Note that progesterone alone does not affect binding but significantly inhibits the stimulatory activity of dexamethasone. 


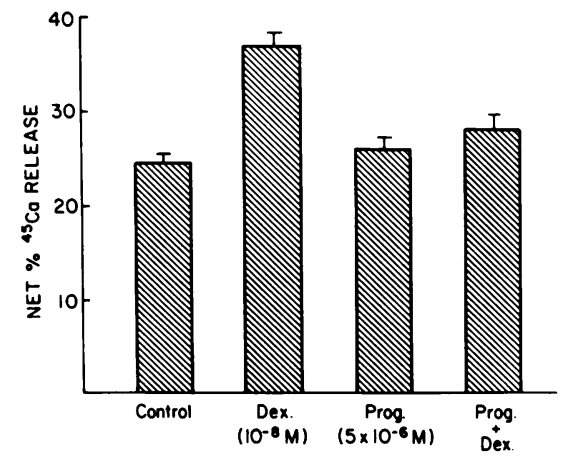

Figure 8. Effect of progesterone on GC-stimulated bone resorption. The resorption assay was performed in the presence of one or both steroids or the ethanol carrier. Note that, as with binding, progesterone alone does not affect resorption but blocks the stimulatory activity of dexamethasone.

promote MO-bone binding and that they do so in a concentration dependent manner which parallels the dose response of GCstimulated, MO-mediated bone resorption (10). Moreover, the attachment-promoting effect appears to be relatively specific in that GC treatment does not increase the ability of MO to bind to plastic, hydroxyapatite, or collagen. In fact, attachment to plastic is clearly reduced by GC treatment.

Cell recognition of, and attachment to, specific substrates are membrane-mediated events and often involve the oligosaccharide moieties of cell surface glycoproteins (for review see reference 15). This clearly seems to be the case for MO-bone binding $(12,16)$ and it is, in fact, by altering cell surface oligosaccharides that GC appear to affect the attachment process. This conclusion follows from two series of experiments, the first of which involved the use of inhibitors of glycosylation. We observed that preincubation of MO with TM (at a concentration that decreases $\left[{ }^{3} \mathrm{H}\right]$ mannose but not $\left[{ }^{3} \mathrm{H}\right]$ leucine incorporation [12]) leads to suppression of basal cell-bone attachment and completely abrogates GC stimulation of such binding. We obtained identical results with SW, an $\alpha$-mannosidase inhibitor that prevents the processing of high mannose to complex glycoproteins (17).

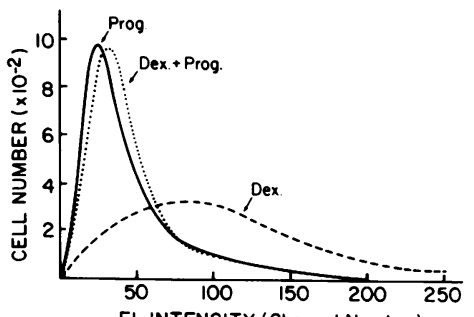

Figure 9. Effect of progesterone on FITC-DBA binding by MO. The cells were preincubated with progesterone $\left(10^{-6} \mathrm{M}\right)$, dexamethasone $\left(10^{-8} \mathrm{M}\right)$, or both steroids for $48 \mathrm{~h}$ and then assayed for lectin binding. Progesterone alone does not affect the binding pat-

tern (curve superimposable on control values) but blocks the shift in lectin attachment normally associated with dexamethasone.
Having established a role for membrane glycosylation in GC-stimulated MO-bone attachment, we turned next to the specific sugars involved. In a previous study, we had found that GlcNAc and GalNAc residues are essential to MO-bone binding (12), and we therefore determined whether GC mediate their effect by increasing exposure of these cell-surface saccharides. The present experiments demonstrate that membrane binding of those lectins (DBA, SBA, WGA, and GSA-2) that specifically recognize either GlcNAc or GalNAc is increased after GC treatment. These observations indicate that the steroids enhance exposure of these sugars in the MO membrane, and are consistent with findings of altered glycosylation in GC-treated cells (18, 19). Furthermore, Ramachandran et al. (20) have recently presented evidence that dexamethasone stimulates glycoprotein synthesis as well as the production of dolichol, dolichol phosphate, and dolichol-linked mannose in HeLa cells. It should be understood, however, that our experiments demonstrate only enhanced exposure of specific membrane sugars by GC treatment of MO; whether this phenomenon also entails stimulated glycosylation is still unclear.

GC are traditionally believed to exert their effects via specific cytosolic receptors which interact with DNA to alter transcriptional activity. On the other hand, some evidence has accumulated which indicates that not all GC effects are receptor mediated (for review see reference 21 ). Although our study did not directly examine this question, it is interesting that the doses of the GC that enhance bone binding and resorption are in the range of the reported affinity constants of the GC for their receptors $(22,23)$. In addition, our data show that progesterone, which competes with GC for the cytosolic receptor (24), blocks all the GC-stimulated alterations of MO function assessed in this study.

We are aware that our observations seem to contradict those made in organ culture wherein GC usually suppress bone resorption. To resolve this paradox may require both a reconsideration of the life history of osteoclasts and MOs and the realization that GC may affect developing cells in an entirely different manner than mature ones. Osteoclasts are derived from hematopoietic precursor cells that almost certainly belong to the monocyte-macrophage family $(25,26)$. However, the precise point at which the lineage of osteoclasts diverges from that of MO (if, indeed, it diverges at all) is not known.

It is clear from this study, the work of Fallon, and other unpublished observations from our laboratory, that GC significantly stimulate the resorptive activity of differentiated, nonproliferative cells of the MO family, i.e., of isolated MO, MO polykaryons (multinucleated giant cells), and bona fide osteoclasts. It is equally clear that GC can profoundly inhibit monocyte and macrophage development. For example, administration of these steroids elicits a monocytopenic response in man (27) and experimental animals $(28,29)$; suppresses in vitro the formation of marrow colony forming units $(30,31)$ (the committed stem cell of the monocyte-osteoclast family) and of osteoclasts (32); blocks the differentiation of human monocytes into macrophages 
(33); and inhibits the fusion of rat macrophages in vitro into multinucleated giant cells (unpublished data).

We suggest, therefore, the following solution to the GC-bone resorption paradox wherein GC have two diametrically opposed effects on bone resorption in vivo and in organ culture, i.e., under circumstances where both precursor and differentiated resorptive cells are present. First, they stimulate matrix degradation by mature MO and osteoclasts. This phenomenon is clearly demonstrated by isolated MO and osteoclasts in vitro (and there is no reason to doubt that there is a similar stimulatory effect in more complex tissue situations). Second, GC inhibit the recruitment and differentiation of cells that belong to the MO-osteoclast family. Thus, both in vivo and in organ culture, the net effect of GC would reflect a summation and thus a balance of both stimulatory and inhibitory activities, with the inhibition of resorption ultimately predominating as osteoclasts are lost through the aging process.

It is interesting to consider this hypothesis in light of the recent observations of Glowacki (34) on the fate of ectopically implanted bone in cortisone-treated rats. Animals given the steroid concurrently with implantation showed almost complete inhibition of the induction of resorbing cells and, consequently, the degradation of the foreign mineralized matrix. On the other hand, if the introduction of cortisone was delayed until after the recruitment of resorptive cells (7-11 days), the presence of the steroid significantly stimulated resorptive activity.

\section{Acknowledgments}

This work was supported by National Institutes of Health grants DE05413 and DE-04629.

\section{References}

1. Bressot, C., P. J. Meunier, M. C. Chapuy, E. Lejeune, and C. Darby. 1979. Histomorphometric profile, pathophysiology and reversibility of corticosteroid-induced osteoporosis. Metab. Bone Dis. Relat. Res. 1:303-311.

2. Hahn, T. J., L. R. Halstead, S. L. Teitelbaum, and B. H. Hahn. 1979. Altered mineral metabolism in glucocorticoid-induced osteopenia. J. Clin. Invest. 64:655-665.

3. Simmons, D. J., and A. S. Kunin. 1967. Autoradiographic and biochemical investigations of the effect of cortisone on the bones of the rats. Clin. Orthop. Relat. Res. 55:201-215.

4. Epker, B. N. 1970. Studies on bone turnover and balance in the rabbit. I. Effects of hydrocortisone. Clin. Orthop. Relat. Res. 72:315326.

5. Raisz, L. G., C. L. Trummel, J. A. Wener, and H. Simmons. 1972. Effects of glucocorticoids on bone resorption in tissue culture. Endocrinology. 90:961-967.

6. Jee, W. S. S., E. L. Blackwood, N. L. Dockum, R. K. Haslam, and F. A. Kincl. 1966. Bio-assay of responses of growing bones in cortisol. Clin. Orthop. Relat. Res. 49:39-63.
7. Jee, W. S. S., W. E. Roberts, H. Z. Park, G. Julian, and M. Kramer. 1972. Interrelated effects of glucocorticoids and parathyroid hormone upon bone remodeling. In Calcium, Parathyroid Hormone and the Calcitonins. R. V. Talmage and P. L. Munson, editors. Excerpta Medica Foundation, Amsterdam. 430-493.

8. Storey, E. 1961. Cortisone-induced bone resorption in the rabbit. Endocrinology. 68:533-542.

9. Birkenhager, J. C., R. O. van der Heul, D. Smeenk, J. van der Sluys Veer, and A. P. van Seters. 1967. Bone changes associated with glucocorticoid excess. Proc. R. Soc. Med. 60:1134-1136.

10. Teitelbaum, S. L., J. D. Malone, and A. J. Kahn. 1981. Glucocorticoid enhancement of bone resorption by rat peritoneal macrophages in vitro. Endocrinology. 108:795-799.

11. Kahn, A. J., J. D. Malone, and S. L. Teitelbaum. 1981. Osteoclast precursors, mononuclear phagocytes and bone resorption. Trans. Assoc. Am Physicians. 94:267-278.

12. Bar-Shavit, Z., S. L. Teitelbaum, and A. J. Kahn. 1983. Saccharides mediate the attachment of rat macrophages to bone in vitro. J. Clin. Invest. 72:516-525.

13. Teitelbaum, S. L., C. C. Stewart, and A. J. Kahn. 1979. Rodent peritoneal macrophages as bone resorbing cells. Calcif. Tissue Int. 27:255261.

14. Goldman, R., and Z. Bar-Shavit. 1979. A dual effect of normal and stimulated macrophages and their conditioned media on target cell proliferation. J. Natl. Cancer Inst. 63:1009-1016.

15. Sharon, N. 1983. Surface carbohydrates and surface lectins are recognition determinants in phagocytosis. Immunol. Today. In press.

16. Bar-Shavit, Z., A. J. Kahn, and S. L. Teitelbaum. 1983. Defective binding of macrophages to bone in rodent osteomalacia and vitamin $\mathrm{D}$ deficiency. J. Clin. Invest. 72:526-534.

17. Dorling, P. R., C. R. Huxtable, and S. M. Colegate. 1980. Inhibition of lysosomal $\alpha$-mannosidase by swainsonine, and indolizidine alkaloid isolated from swainsona canescens. Biochem. J. 191:649-651.

18. Tu, S.-H., R. E. Nordquist, and M. J. Griffin. 1972. Membrane changes in HeLa cells grown with cortisol. Biochim. Biophys. Acta. 290:92-109.

19. Pietras, R. J., and C. M. Szego. 1975. Surface modifications evoked by estradiol and diethylstilbesterol in isolated endometrial cells: evidence from lectin probes and extracellular release of lysosomal protease. Endocrinology. 97:1445-1454.

20. Ramachandran, C. K., C. E. Hignite, S. L. Gray, and G. Melanykovich. 1981. Evidence for stimulation of dolichol and mannolipids synthesis by glucocorticoids in HeLa cells. Biochem. J. 198:23-28.

21. Duval, D., S. Durrant, and F. Homo-Delarche. 1983. Non-genomic effects of steroids: interactions of steroid molecules with membrane structures and functions. Biochem. Biophys. Acta. 737:409-442.

22. Werb, Z., R. Foley, and A. Munck. 1978. Glucocorticoid receptors and glucocorticoid-sensitive secretion of neutral proteinases in a macrophage line. J. Immunol. 121:115-121.

23. Werb, Z. 1978. Biochemical actions of glucocorticoids on macrophages in culture. J. Exp. Med. 147:1695-1712.

24. Werb, Z., R. Foley, and A. Munck. 1978. Interaction of glucocorticoids with macrophages. J. Exp. Med. 147:1684-1694.

25. Ko, J. S., and G. W. Bernard. 1981. Osteoclast formation in vitro from bone marrow mononuclear cells in osteoclast-free bone. Am. J. Anat. 161:415-425. 
26. Burger, E. H., J. W. M. van der Meer, J. S. van de Gevel, J. C. Gribnau, C. Wil Thesingh, and R. van Furth. 1982. In vitro formation of osteoclasts from long-term cultures of bone marrow mononuclear phagocytes. J. Exp. Med. 156:1604-1614.

27. Cupps, T. R., and A. S. Fauci. 1982. Corticosteroid-mediated immunoregulation in man. Immunol. Rev. 65:133-155.

28. Thompson, J., and R. van Furth. 1971. The effect of glucocorticosteroids on the kinetics of mononuclear phagocytes. J. Exp. Med. 131:429-442.

29. Thompson, J., and R. van Furth. 1973. The effect of glucocorticosteroids on the proliferation and kinetics of promonocytes and monocytes of the bone marrow. J. Exp. Med. 137:10-21.

30. Motomura, S., M. Katsuno, S. Kaneko, and H. Ibayashi. 1983. The effect of hydrocortisone on the production and differentiation of granulocyte/macrophage progenitor cells in long-term bone marrow cultures. Exp. Hematol. (Copenhagen). 11:56-62.

31. Ishii, Y., M. Shinoda, and M. Shikita. 1983. Specificity of the suppressive action of glucocorticoids on the proliferation of monocyte/ macrophages in the CSF-stimulated cultures of mouse bone marrow. Exp. Hematol. (Copenhagen). 11:178-186.

32. Suda, T., N. G. Testa, T. D. Allen, D. Onions, and O. Jarrett. 1983. Effect of hydrocortisone on osteoclasts generated in cat bone marrow cultures. Calcif. Tissue. Int. 35:82-86.

33. Rinehart, J. J., D. Wuest, and G. A. Ackerman. 1982. Corticosteroid alteration of human monocyte to macrophage differentiation. J. Immunol. 129:1436-1440.

34. Glowacki, J. 1983. Cortisol has two effects on bone resorption. Endocr. Soc. Aust. Proc. 255. (Abstr.) 